\title{
Effect of Selenium on Chlorpyrifos-Induced Thyroid Toxicity in Albino Rats
}

\author{
Hawazen A. Lamfon \\ Department of Biology, Faculty of Applied Sciences, Umm Al-Qura University, Makkah, Saudi Arabia \\ Correspondence should be addressed to: Hawazen A. Lamfon; halamf@uqu.edu.sa
}

Received Date: 30 September 2013; Accepted Date: 25 November 2013; Published Date: 31 March 2014

Academic Editor: Chinnasamy Thirunavukkarasu

Copyright (C) 2014 Hawazen A. Lamfon. Distributed under Creative Commons CC-BY 3.0

\begin{abstract}
The present work studied the effect of the organophosphate insecticide, Chlorpyrifos (CPF) on the thyroid of albino rats and the possible ameliorative role of selenium (Se). Administration of CPF by gastric intubation $\left(1 / 20 \mathrm{LD}_{50}, 6.7 \mathrm{mg} / \mathrm{kg}\right.$ b.w. 5 days / week for 6 weeks) caused many histological alterations in the thyroid There was decrease in the size of follicles and amount of colloid, degeneration of follicular cells and congestion of blood vessels. Decrease of periodic acid Schiff (PAS) reaction in the cytoplasm of the follicular cells and colloids was observed. Besides, CPF caused marked reduction in triiodothyronine $\left(\mathrm{T}_{3}\right)$, thyroxine $\left(\mathrm{T}_{4}\right)$ and thyroid stimulating hormone (TSH). Animals treated with CPF and Se ( $(10 \mu \mathrm{g} / \mathrm{Kg}$ b.w, 5 days / week for 6 weeks) showed great amelioration and normalization of thyroid tissue architecture and increase in the thyroid hormones, $\mathrm{T}_{3}, \mathrm{~T}_{4}$ and TSH. Since CPF toxicity may be due to its ability to induce oxidative stress in thyroid, it is possible that Se supply reversed CPF-induced thyroid toxicity by ameliorating the antioxidative defense of the rats.
\end{abstract}

Keywords: Thyroid, Chlorpyrifos, Selenium, Thyroid hormones.

\section{Introduction}

Organophosphate compounds are the most widely used insecticides accounting for $50 \%$ of global insecticidal use. Chlorpyrifos [0,0-diethyl $\quad 0$-(3,5,6-trichloro-2-pyridyl) phosphorothioate] (CPF) is one of the most widely used organophosphate insecticide and is registered for use in food crops, including fruit and nut trees, many types of fruits and vegetables Public health uses include aerial and ground-based fogger treatments to control mosquitoes (U.S.EPA,2011). Adverse effects have been observed following CPF poisoning. Wang et al. (2009) stated that chlorpyrifos is generally toxic to mammals. Exposure to
CPF induced histopathological alterations in liver (Tripathi and Srivastav, 2010) and kidney (Heikal et al.2012). Human and experimental studies have shown that fetuses and infants are more sensitive than adults to many environmental toxicants including chlorpyrifos and these exposures impact fetal growth and early childhood neurodevelopment (Eskenazi et al.2007). $\mathrm{CPF}$ is considered as an endocrine disrupter. Viswanath et al (2010) described chlorpyrifos as one of the most potent antiandrogenic compounds. They added that Chlorpyrifos significantly decreased biosynthesis of testosterone in rat Leydig cells; it decreased the expression of key steroidogenic enzymes, decreased

Cite this Article as: Hawazen A. Lamfon (2014), "Effect of Selenium on Chlorpyrifos-Induced Thyroid Toxicity in Albino Rats," Research in Endocrinology, Vol. 2014 (2014), Article ID 751500, DOI: $10.5171 / 2014.751500$ 
steroidogenic acute regulatory protein expression, and decreased luteinizing hormone receptor stimulated cAMP (cyclic adenosine monophosphate) production. Ventura et al. (2012). described chlorpyrifos as a breast cancer risk. Rawlings et al. (1998) reported that oral chlorpyrifos significantly reduced serum concentrations of cortisol and thyroxine (T4) in sheep. Haviland et al (2010) found increased thyroid hormone levels and altered learning behaviour in female mice exposed to 1 and $5 \mathrm{mg} / \mathrm{kg}$ chlorpyrifos on gestational days 17-20.

Recent decades have confirmed importance of selenium for mammalian life, with the recognition that selenium coordinates the functioning of certain proteins, designated as selenoproteins. During selenoprotiens synthesis, it is incorporated into a very specific location in the amino acid sequence in order to form a functional protein (Rayman, 2000). At least two types of selenoproteins are necessary for each mammalian cell; the first form is the family of GSH-peroxidase and the second form is the family of deiodinases. Gärtner (2009) reported that the plasma selenium levels indicate the amount of circulating selenoproteins and selenoenzymes which are important for modulating the immune system and also for thyroid hormone metabolism. Thirunavukkarasu and Sakthisekaran, (2003) reported that selenium had antiperoxidative effect and capacity to prevent cancer. Liao et al. (2008) observed that selenium played a beneficial role for prevention of cisplatin hepatotoxicity in mice. Selenium has a protective effect against rat liver and kidney damage induced by mercury chloride (El-Shenawy and Hassan, 2008) and by cadmium (Jihen et al.2008). Sakr et al. (2011) found that selenium ameliorated the testicular damage and oxidative stress induced by carbimazole in albino rats. The present work aims to investigate the effect of selenium on the thyroid toxicity induced by chlorpyrifos in albino rats.

\section{Materials and Methods}

This study was performed on adult male Wistar rats approximately 3 months old and weighing $140 \pm 5 \mathrm{~g}$. The animals were kept in individual special rodent cages in the animal house under constant temperature condition $(25 \pm 3 C)$ with a reverse natural dark and light cycle (12-h dark/12-h light). Animals were maintained on a standard rodent diet composed of $20 \%$ casein, $15 \%$ corn oil, 55\% corn starch, $5 \%$ salt mixture, and $5 \%$ vitamins. Water was available ad libitum. Maintenance of animals and experimental procedures was approved by the animal ethical committee in accordance with the Guide for Care and Use of Laboratory. Animals were divided into four groups:

Group1. Animals of this group served as a control group.

Group2. Animals of this group were orally given sodium selenite $(10 \mu \mathrm{g} / \mathrm{Kg}$ b.w $)$ dissolved in water, 5 days / week for 6 weeks.

Group3. Animals of this group were orally administrated with CPF dissolved in corn oil at a dose level of $1 / 20 \mathrm{LD}_{50}(6.7 \mathrm{mg} / \mathrm{kg}$ b.w.), 5 days / week for 6 weeks.

Group4. Rats were given $1 /{ }_{20} \mathrm{LD}_{50} \mathrm{CPF}$ and sodium selenite $(10 \mu \mathrm{g} / \mathrm{Kg}$ b.w $)$ for 6 weeks.

\section{Histopathological and Morphometrical Examination}

The treated animals and their controls were killed by cervical disslocation, quickly dissected and their thyroids were removed and fixed in Bouin's fluid, dehydrated, and embedded in wax and 5 micrometers thick sections were stained with haematoxylin and counterstained with eosin. Another sections were stained with periodic acid Schiff (PAS) reaction for mucopolysaccharides (Kierman, 1999). Diameters of thyroid follicles were measured in $\mathrm{H}$ and $\mathrm{E}$ sections using an ocular micrometer. Percentage of follicles with normal content of colloid was measured in PAS-stained sections. These measurements were done in 10 fields of each specimen. 


\section{Hormonal Assay}

For biochemical study sera were obtained by centrifugation of the blood samples and stored at $-20^{\circ} \mathrm{C}$. Serum concentrations of triiodothyronine $\left(\mathrm{T}_{3}\right)$, thyroxine $\left(\mathrm{T}_{4}\right)$ and thyroid stimulating hormone (TSH) were estimated by radioimmunoassay using the method of Evered et al. (1973).

\section{Statistical Analysis}

Data are expressed as mean values \pm SD. Statistical analysis was performed using one-way analysis of variance (ANOVA) to assess significant differences among treatment groups. The criterion for statistical significance was set at $\mathrm{P}<0.05$. All statistical analyzes were performed using SPSS statistical version 8 software package (SPSSInc., USA).

\section{Results}

\section{Microscopic Changes}

Examination of sections of thyroid of control rats stained with haematoxyline and eosin showed that it composed of follicles of different shapes and sizes. The follicles were oval or round in shape and its wall consisted of a single layer of cuboidal cells with eosinophilic cytoplasm and basophilic nuclei. The lumen of the follicle is filled with colloid. The interfollicular spaces showed numerous blood capillaries and connective tissue (Fig.1a). Treating animals with CPF showed follicles with irregular outlines and their walls were lined by flattened cells. Lumens of large number of follicles contained few and diffused colloid, other follicles were devoid of colloid (Fig.1b). The lining epithelia appeared with hyperplasia (Fig.1c). The interfollicular connective tissue was degenerated (Fig.2a). The blood vessels were dilated and congested (Fig.2b). Animals treated with $\mathrm{CPF}$ and selenium showed great amelioration and normalization of thyroid tissue architecture, the follicles similar in shape to that of controls and are lined by cuboidal epithelium (Fig.2c. Thyroid gland of control rats stained by PAS showed moderately stained cytoplasm of follicular epithelia and strong stained colloid (Fig.3a). Animals treated with CPF showed follicles devoid of colloid and decrease of PAS reaction in the cytoplasm of the follicular cells (Fig.3b). Administration of CPF and selenium caused an increase in PAS reaction in the cytoplasm of the follicular cells and colloid (Fig.3c). 


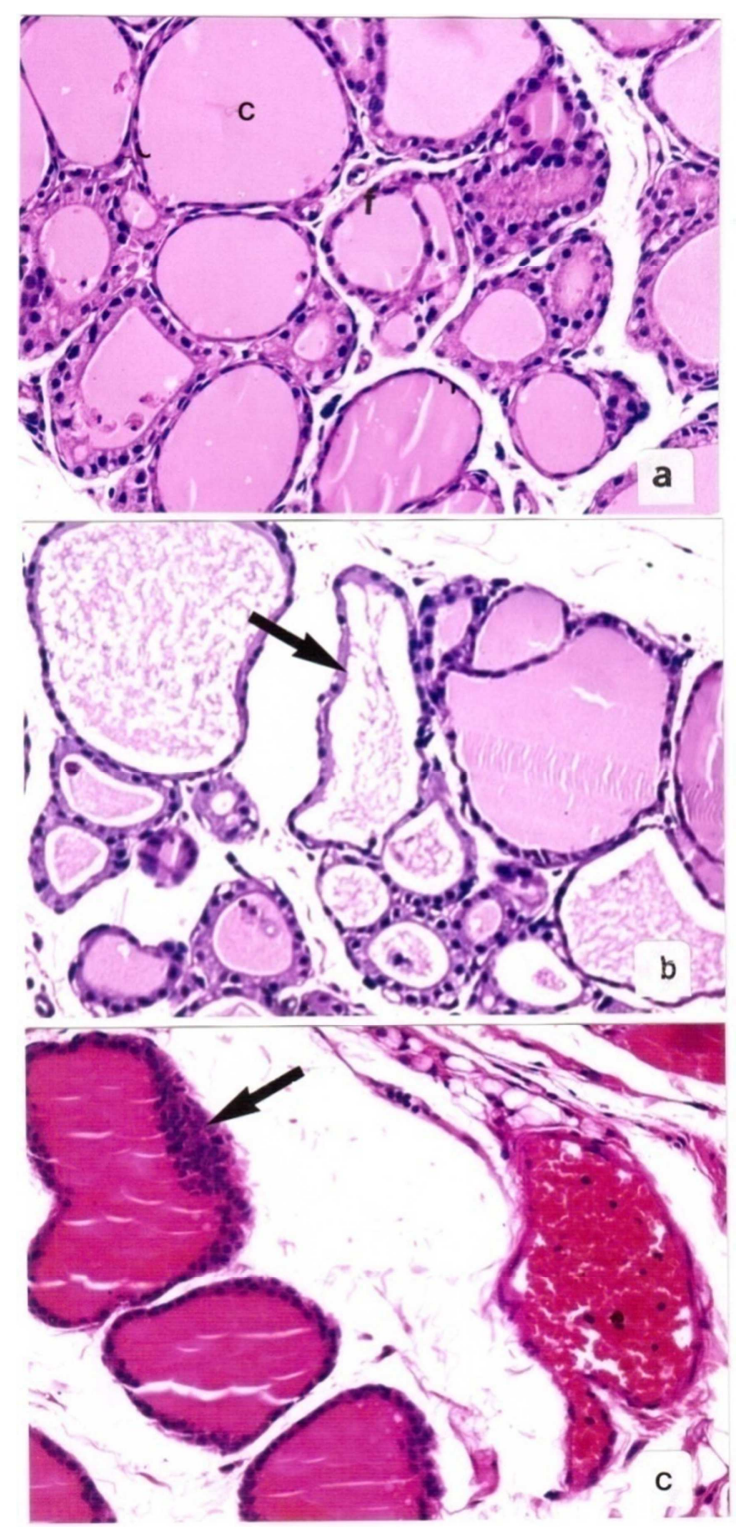

Fig. 1. a) Section in Thyroid of a Control Rat Showing Follicles, C: Colloid, f: Follicular Epithelium.

b) Thyroid of CPF-Treated Rat Showing Irregular Follicles Devoid of Colloid. c) Hyperplasia of Epithelium, X 300. 


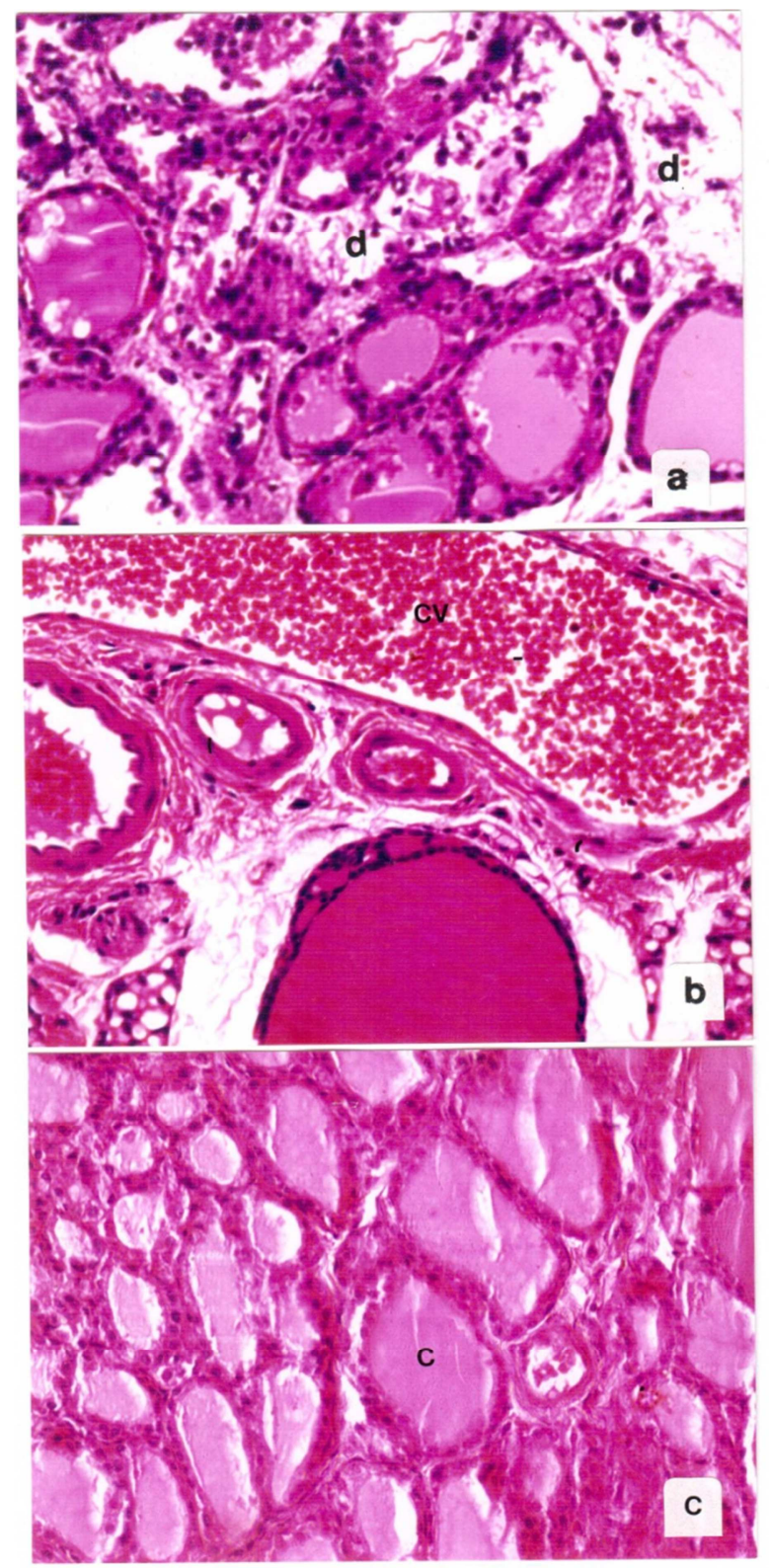

Fig. 2.a) Thyroid of a CPF Treated Rat Showing Degenerated Connective Tissue (D), X300. b) Enlarged and Congested Vein (CV), X 400.

c) Thyroid of a Rat Treated with CPF and Se Showing Improved Follicles Filled with Colloid, X 300. 


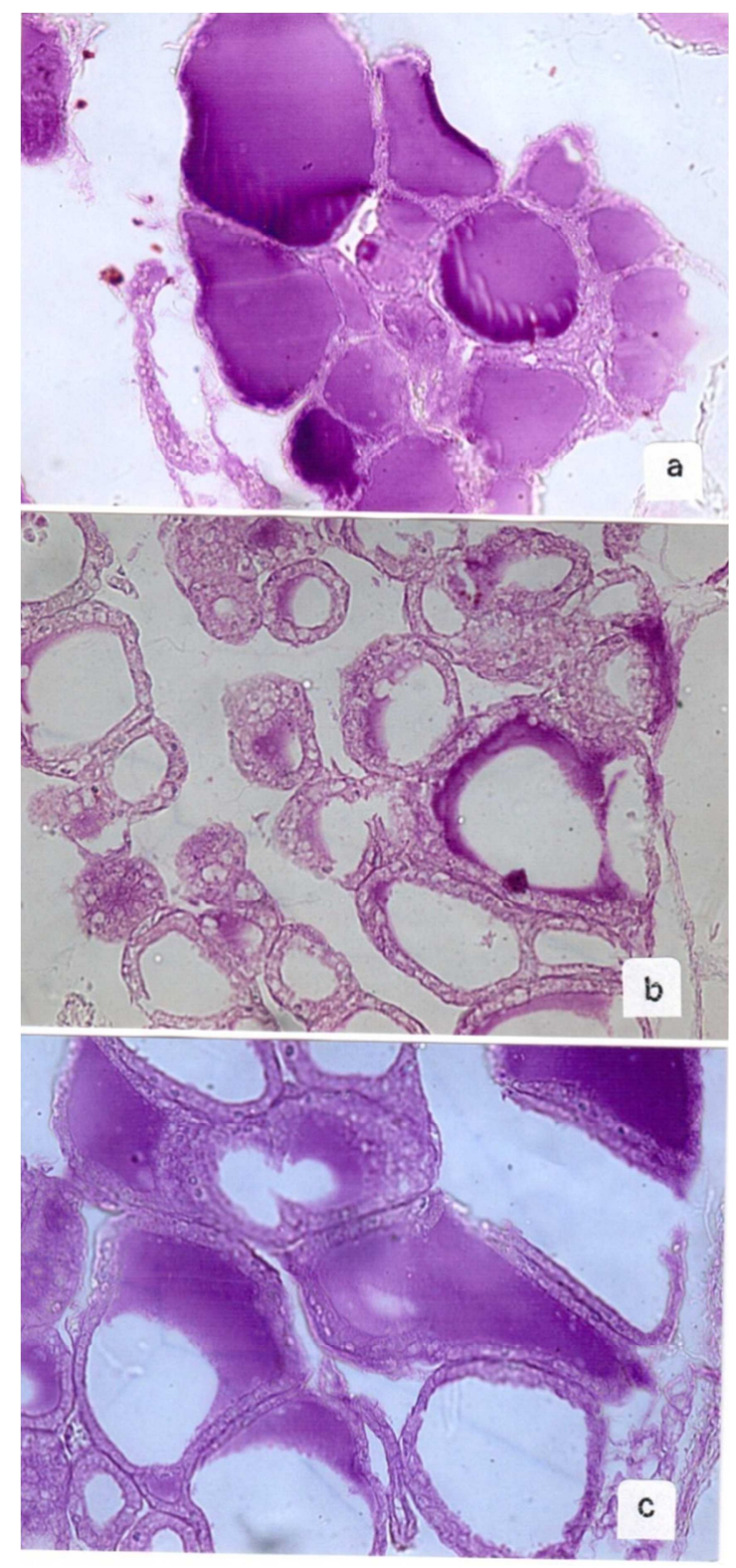

Fig. 3. a) Thyroid of a Control Rat Showing PAS Reaction in the Colloid and Follicular Epithelia

b) Thyroid of CPF-Treated Rat Showing Decrease of PAS Reaction.

C) Thyroid of a Rat Treated with CPF and Se Showing Decrease of PAS Reaction, X 300.

\section{Morphometrical Results}

Data in figure $4 \mathrm{a}$ showed that there is significant decrease in follicles diameter $(21.4 \pm 1.6 \mu)$ in CPF-treated animals compared with that in controls $(31.5 \pm 2.1 \mu)$. On the other hand, coadministration of Se caused an increase in the diameter of the follicles. Similarly, percentage of follicles with normal content of colloid decreased in CPF-treated rats $(48 \pm 8.2 \%)$ and increased $(70 \pm 4.8 \%)$ after treatment with Se (Fig.4b). No significant difference was recorded between controls and Se groups. 

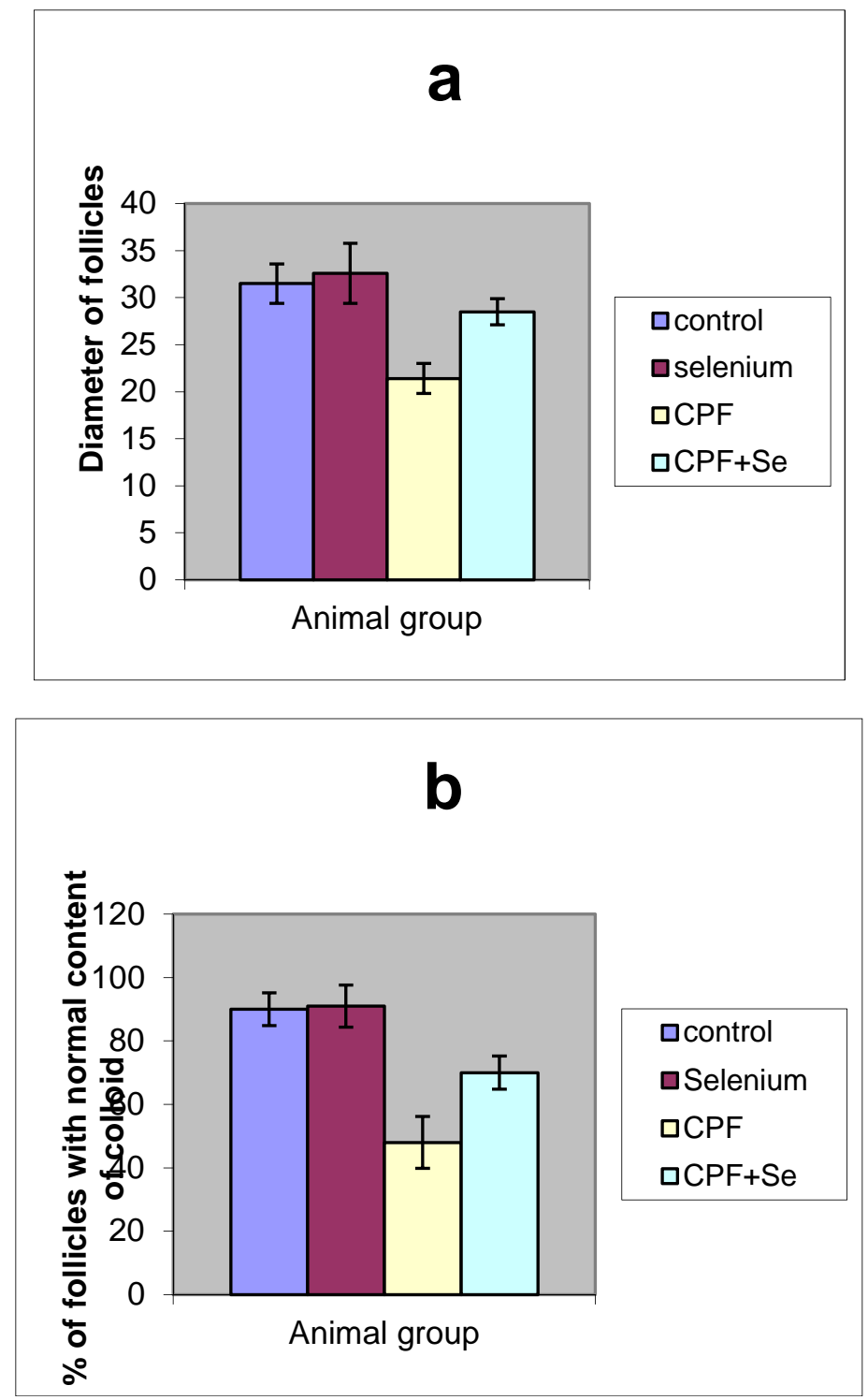

Fig. 4. Change in (a) Diameter of Follicles and (b) \% of Follicles with Normal Content of Colloid in Different Animal Groups.

\section{Hormonal Results}

Treating animals with CPF for 6 weeks showed a significant reduction $(\mathrm{P}<0.05)$ in serum $\mathrm{T}_{3}, \mathrm{~T}_{4}$ and TSH in comparison with control group (Fig.5).Treatment with CPF and Se caused significant increase $(\mathrm{P}<0.05)$ in serum level of these hormones in comparison with rats treated with $\mathrm{CPF}$. There was insignificant increase in levels of $\mathrm{T}_{3}, \mathrm{~T}_{4}$ and $\mathrm{TSH}$ in sera of animals treated with Se in comparison with control group. 


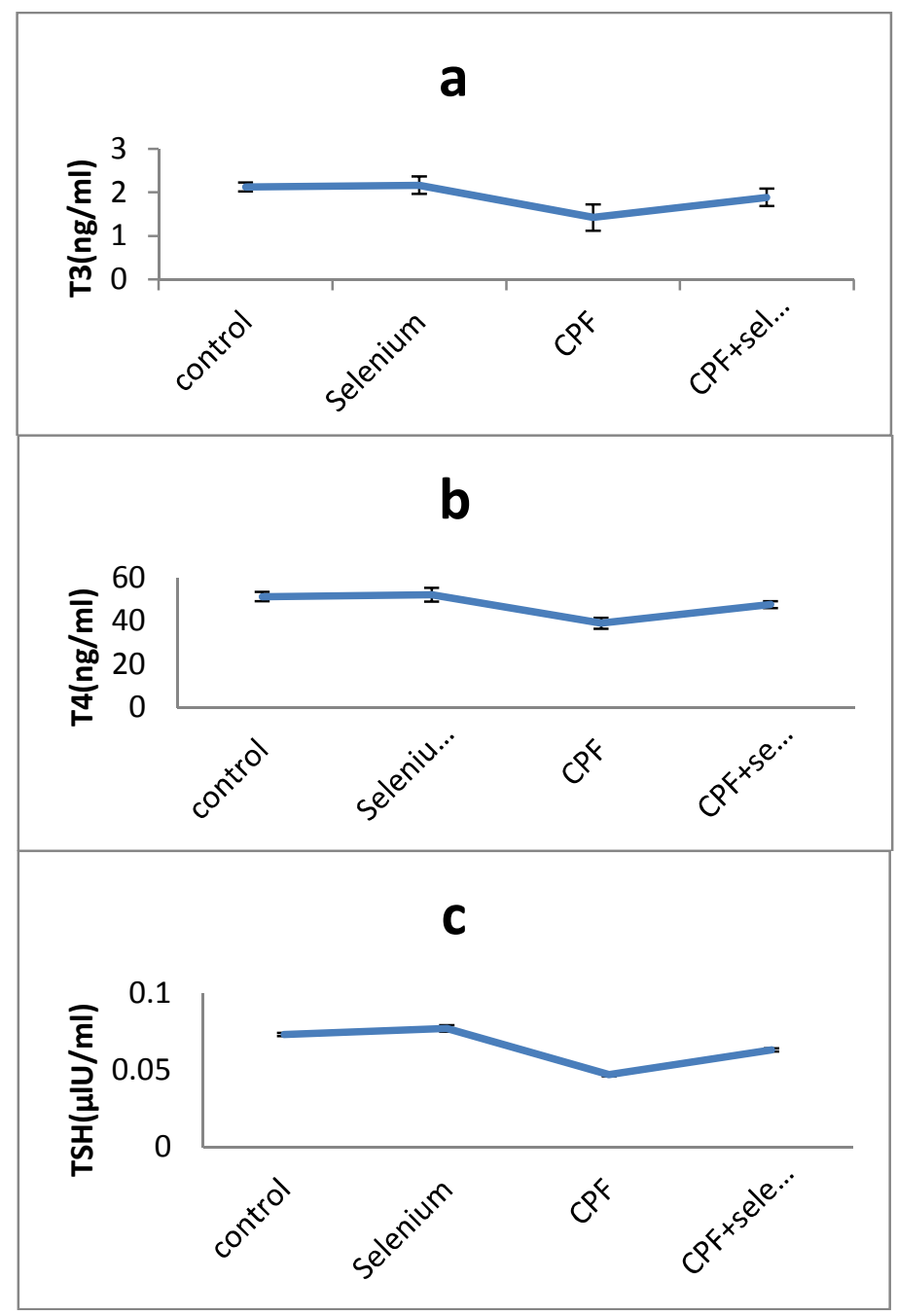

Fig. 5. Change in T3, T4 and TSH in Different Animal Groups

\section{Discussion}

The present results indicated that $\mathrm{CPF}$ affected structure and function of thyroid gland in albino rats. There was decrease in the size of follicles and amount of colloid, degeneration of follicular cells and congestion of blood vessels. Polysaccharides content was decreased. Sera of rats treated with CPF revealed a significant decrease in $\mathrm{T}_{3}, \mathrm{~T}_{4}$ and $\mathrm{TSH}$. In agreement with this result, De Angelis et al. (2009) reported that serum T3 and T4, was reduced in pregnant mice, and their offspring once they had reached adulthood, at levels of exposure to chlorpyrifos that did not induce brain acetylcholinesterase inhibition or other signs of toxicity. It also induced histopathological alterations in the thyroid gland in both generations. Shady and Noor El-Din (2010) reported that CPF treated rats showed hypothyroidism which was evidenced biochemically by a very highly significant decrease in serum T3 and T4 levels, histologically by decreased amount of colloid, histochemically by decreased PAS reaction in the colloid and immunohistochemically by a weak thyroglobulin protein expression in the colloid. Ambali et al. (2011) recorded a non-significant decrease in the serum level of T3and T4, and significant increase in TSH in rats exposed to CPF. Meeker et al. (2006) observed an inverse association between urinary concentration of CPF metabolites, 3, 5, 6-trichloro-2-pyridinol and T4 level and a positive association with TSH. Jeong et al. (2006) reported that 
treating rats with $\mathrm{CPF}$ during pregnancy and for 13 weeks after birth caused necrosis of thyroid follicular cells with subsequent decrease in thyroid hormones.

The mechanism by which CPF induced decrease in secretion of thyroid hormones is not clear. Previous studies suggested that insecticides may decrease iodine binding proteins (Balasubramanian et al.1986). Oxidative stress is one of the possible mechanisms resulted from organophosphate toxicity, including CPF. Ahmed and Zaki (2009) reported that CPF may have properties to induce oxidative stress indicated by enhancement of MDA production, decrease in GSH content, GST and CAT activities in rat tissues. Thus the inhibitory effect of CPF on thyroid function observed in the present work could be attributed to deficient iodide trapping or oxidative stress of CPF.

Treatment with Se has been shown by the present study to improve the thyroid structure and function changes induced by administration of $\mathrm{CPF}$. The relationship between Se and thyroid function has been investigated. Beckett and Arthu (2005) reported that $\mathrm{Se}$ is essential for normal thyroid function and acts as an antioxidant in the thyroid and a regulator of triiodothyronine (T3) production. It has been demonstrated that Se has a central role as supplementary therapy in Graves's disease because of its action through selenoenzymes both on transforming of the thyroid hormones and on the antioxidative defense of the organism (Vrca et al.2004). Hammouda et al. (2008) reported that the treatment of cadmium-exposed rats with Se partially protected from the cadmium induced decrease in serum $\mathrm{T}_{4}$ level and increase in serum TSH level.

Oxidative stress occurs when production or exposure to reactive oxygen species (ROS) outstrips the ability of the cell to remove them. This can occur by an increase in ROS production or a decrease in the ability of the cell to metabolisze them (Cerutti, 1985). Excess production of ROS in cells resulted in several biological effects. It was stated that Se could counteract the function of ROS, directly scavenge superoxide anion, hydroxyl radicals, peroxyl radical species and nitric oxide compared to the control group. Hassanin et al. (2013) reported that Se have a protective effect on $\mathrm{K}_{2} \mathrm{Cr}_{2} \mathrm{O}$ induced thyroid damage, as a result of correcting the free $\mathrm{T}_{3}$ and $\mathrm{T}_{4}$ levels and $\mathrm{GSH}$, catalase, SOD, and MDA compared to the $\mathrm{K}_{2} \mathrm{Cr}_{2} \mathrm{O}$-treated group. Santos and Takahashi (2008) reported that the mechanism of chemoprotection of selenium may be related to its antioxidant properties as well as its ability to interfere with DNA repair pathways. Flora et al. (2002) stated that the most important metabolic roles of selenium in mammalian cell are due to its function in the active site of many antioxidant enzymes; like thioredoxin reductase, glutathione peroxidase and glutathione reductase. $\mathrm{Yu}$ et al. (2006) reported that selenium inhibited oxidative stress, apoptosis and cell cycle changes induced by excess fluoride in kidney of rats. Sakr et al. (2012) reported that Se ameliorated carbimazoleinduced hepatotoxicity in rats and decreased lipid peroxidation and increase the level of antioxidant enzymes SOD and CAT.

\section{Conclusion}

It is concluded from the results of the present work that CPF toxicity may be due to its ability to induce oxidative stress in thyroid and it is possible that the administration of Se could inhibit CPFinduced thyroid toxicity by boosting the antioxidative defense of the rats.

\section{References}

Ahmed, M. M. \& Zaki, N. I. (2009). "Assessment the Ameliorative Effect of Pomegranate and Rutin on ChlorpyrifosEthyl-Induced Oxidative Stress in Rats," Nature and Science. 7(10):49-61.

Ambali, S. F., Orieji, C., Abubakar, W. O., Shittu, M. \& Kawu, U. M. (2011). "Ameliorative Effect of Vitamin C on Alterations in Thyroid Hormones Concentrations Induced by Subchronic Co Administration of Chlorpyrifos and Lead in Wistar Rats," Journal of Thyroid Research. 2011:1-6. 
Balasubramanian, K., Vijayan, A. P., Ananthanaryan, P. H. \& Balasubramanian, A. (1989). 'Effect of Malathion on the Thyroid Function of Male Albino Rats,' IRCS Journal of Medical Science, 14:1139-1149.

Beckett, G. J. \& Arthur, J. R. (2005). "Selenium and Endocrine Systems," Journal of Endocrinology 184:455-465.

Cerutti, P. A. (1985). "Prooxidant States and Tumor Promotion," Science 227:375-381.

De Angelis, S., Tassinari, R., Maranghi, F., Eusepi, A., Di Virgilio, A., Chiarotti, F., Ricceri, L., Pesciolini, A. V., Gilardi, E., Moracci, G., Calamandrei, G., Olivieri, A. \& Mantovani, A. (2009). "Developmental Exposure to Chlorpyrifos Induces Alterations in Thyroid and Thyroid Hormone Levels without Other Toxicity Signs in Cd1 Mice," Toxicological Sciences 108(2):311-9.

El-Shenawy, S. M. \& Hassan, N. S. (2008). "Comparative Evaluation of the Protective Effect of Selenium and Garlic Against Liver and Kidney Damage Induced by Mercury Chloride in the Rats," Pharmacological Reports 60(2):199-208.

Eskenazi, B., Marks, A. R., Bradman, A., Harley, K., Barr, D., Johnson, C. \& Jewell, N. (2007). "Organophosphate Pesticide Exposure and Neurodevelopment in Young Mexican-American Children," Environmental Health Perspectives, 115(5), 792-798.

Evered, D. C., Osrmton, B. C., Smith, P. A., Hail, R. \& Bird, T. (1973). "Grades of Hypothyroidism," British Medical Journal, 1:657-62.

Flora, S. J., Kannan, G. M., Pant, B. P. \& Jaiswal, D. K. (2002). "Combined Administration of Oxalic Acid, Succimer and Its Analogue for the Reversal of Gallium Arsenide Induced Oxidative Stress in Rats," Archives of Toxicology. 76(56):269-276.

Gärtner, R. (2009). "Selenium and Thyroid Hormone States: An Overview of Conflicting View Points," Journal of Trace
Elements in Medicine and Biology, 23(2):71-4.

Hammouda, F., Messaoudi, I., El Hani, J., Baati T., Saïd, K. \& Kerkeni, A. (2008). "Reversal of Cadmium-Induced Thyroid Dysfunction by Selenium, Zinc, or Their Combination in Rat," Biological Trace Element Research 126:194-203.

Hassanin, K. M. A., Abd El-Kawi, S. H. \& Hashem, K. S. (2013). "The Prospective Protective Effect of Selenium Nanoparticles against Chromium-Induced Oxidative and Cellular Damage in Rat Thyroid," International Journal of Nanomedicine 8: 1713-1720.

Haviland, J. A., Butz, D. E. \& Porter, W. P. (2010). "Long-Term Sex Selective Hormonal and Behaviour Alterations in Mice Exposed to Low Doses of Chlorpyrifos in Utero," Reproductive Toxicology 29(1):74-9.

Heikal, T. M., Mossa, A. T. H., Marei, G. I. K., Abdel Rasoul, M. A. (2012). "Cyromazine and Chlorpyrifos Induced Renal Toxicity in Rats: The Ameliorating Effects of Green Tea Extract," Journal of Environmental \& Analytical Toxicology 2(5):1-7.

Jeong, S. H., Kim, B. Y., Kang, H. G., Ku, H. O. \& Cho, J. H. (2006). "Effect of ChlorpyrifosMethyl on Steroid and Thyroid Hormones in Rat F0- and F1-Generations," Toxicology, 220(2-3):189-202.

Jihen, E. H., Imed, M., Fatima, H. \& Abdelhamid, K. (2008). "Protective Effects of Selenium (Se) and Zinc (Zn) on Cadmium (Cd) Toxicity in the Liver and Kidney of the Rat: Histology and Cd Accumulation," Food and Chemical Toxicology 46(11):3522-7.

Kiernan, J. A. (1999). Histological and Histochemical Methods: Theory and Practice, 3rd Ed.Butterworth-Heinemann: Oxford.

Liao, Y., Lu, X., Lu, C., Li, G., Jin, Y. \& Tang, H. (2008). "Selection of Agents for Prevention of Cisplatin-Induced Hepatotoxicity," Pharmacological Research 57(2):125-31. 
Meeker, J. D., Ryan, L., Barr, D. B. \& Hauser, R. (2006). "Exposure to Nonpersistent Insecticides and Male Reproductive Hormones," Epidemiology, 17(1): 61-68.

Rawlings, N. C., Cook, S. J. \& Waldbillig, D. (1998). "Effects of the Pesticides Carbofuran, Chlorpyrifos, Dimethoate, Lindane, Triallate, Trifluralin, 2.4-D, and Pentachlorophenol on the Metabolic Endocrine and Reproductive Endocrine System in Ewes," Journal of Toxicology and Environmental Health, Part A: 54:21-36.

Rayman, M. P. (2000). "The Importance of Selenium to Human Health," The Lancet 356:233-241.

Sakr, S. A. R., Abdel-Ghafar, F. R. \& Abo-ElYazid, S. A. (2012). 'Protective Effect of Selenium on Carbimazole Induced Hepatotoxicity in Albino Rats,' Archives Des Sciences Journal, 65(11):257-267.

Sakr, S. A. R., Mahran, H. A. \& Nofal, A. E. (2011). "Effect of Selenium on Carbimazole-Induced Testicular Damage and Oxidative Stress in Albino Rats," Journal of Trace Elements in Medicine and Biology. 25: 59-66.

Santos, R. A. \& Takahashi, C. S. (2008). "Anticlastogenic and Antigenotoxic Effects of Selenomethionine on DoxorubicinInduced Damage in Vitro in Human Lymphocytes," Food and Chemical Toxicology, 46(2):671-677.

Shady, A. M. \& Noor El-Deen, F. I. (2010). "Effect of Chlorpyrifos on Thyroid Gland of Adult Male Albino Rats," Egyptian Journal of Histology. 33(3): 441 - 450.

Thirunavukkarasu, C. \& Sakthisekaran, D. (2003). "Sodium Selenite, Dietary Micronutrient, Prevents the Lymphocyte DNA Damage Induced by $\mathrm{N}$ Nitrosodiethylamine and Phenobarbital Promoted Experimental Hepatocarcinogenesis," Journal of Cellular Biochemistry, 88(3):578-88.
Tripathi, S. \& Srivastav, A. K. (2010). "Liver Profile of Rats after Long-Term Ingestion of Different Doses of Chlorpyrifos," Pesticide Biochemistry and Physiology 97(1):60-65.

U.S. Environmental Protection Agency. Chlorpyrifos Facts, (2011) http://www.epa.gov/oppsrrd1/REDs/facts heets/chlorpyrifos_fs.htm

Ventura, C., Nú-ez, M., Miret, N., Lamas, D. M., Randi, A., Venturino, A., Rivera, E. \& Cocca, C. (2010). "Differential Mechanisms of Actions are Involved in Chlorpyrifos Effects in Estrogen-Dependent orIndependent Breast Cancer Cells Exposed to Low or High Concentrations of Pesticide," Toxicology Letters 213:184-193.

Viswanath, G., Chatterjee, S., Dabral, S., Nanguneri, S. R., Divya, G. \& Roy, P. (2010). "Anti-Androgenic Endocrine Disrupting Activities of Chlorpyrifos and Piperophos," The Journal of Steroid Biochemistry and Molecular Biology, 120:22-9.

Vrca, V. B., Skerb, F., Cepelak, I., Romic, Z. \& Mayer, L. (2004). "Supplementation with Antioxidants in the Treatment of Graves' Disease; the Effect $\mathrm{O} N$ Glutathione Peroxidase Activity and Concentration of Selenium," Clinica Chimica Acta 341:55-63.

Wang, H. P., Liang, Y. J., Long, D. X., Chen, J. X., Hou, W. Y. \& Wu, Y. J. (2009). "Metabolic Profiles of Serum from Rats after Subchronic Exposure to Chlorpyrifos and Carbaryl," Chemical Research in Toxicology. $22: 1026-1033$.

Yu, R. A., Xia, T., Wang, A. G. \& Chen, X. M. (2006). "Effects of Selenium and Zinc on Renal Oxidative Stress and Apoptosis Induced by fluoride in Rats," Biomedical and Environmental Sciences 19(6):439-44. 